(RESEARCH ARTICLE)

\title{
Structural floor shape efficiency of circular and square high rise structure towards lateral loadings
}

\author{
Md Mehedi Hasan 1, 2, , Meskat Jamil 2, and Md Mahbub-ul-Alam ${ }^{2}$ \\ ${ }^{1}$ School of Civil Engineering and Architecture, Kunming University of Science and Technology 650500, China \\ ${ }^{2}$ Department of civil Engineering, Stamford University Bangladesh, Dhaka-1217, Bangladesh.
}

Publication history: Received on 29 September 2020; revised on 22 October 2020; accepted on 24 October 2020

Article DOI: https://doi.org/10.30574/wjarr.2020.8.1.0364

\begin{abstract}
The building shape is one of the most important considerations in the conceptual stage of building design. Since the building shape determines the size and the orientation of the exterior envelope exposed to the outdoor environment, it can affect building performance in many aspects: energy efficiency, cost and aesthetics. The shape and exterior structure of a house play major roles in determining its energy efficiency and the comfort of residents. The shape is comprised of the building's height, width, and depth-also known as the footprint.

The determination of the structural shape of a high-rise building would preferably involve only the selection and arrangement of the major structural element to resist most efficiently the various combinations of gravity and horizontal loading. Based on the above considerations, this study focuses on the responses by analysing the effects of the lateral loads on two 20 storied high rise structures having edge supported floor systems each of which one with square floor shape and another with circular floor and finally, presents a comparative result.
\end{abstract}

Keywords: Conceptual; Determination; Horizontal; Envelope; Comparative; Structural

\section{Introduction}

High-rise buildings, which are developed as a response to population growth, rapid urbanization and economic cycles, are indispensable for a metropolitan city development. This statement holds true for today; however, the relationship between cost and benefit is more complex in today's global marketplace. The political ideology of the city plays an important role in the globalization process [1,2]. The current trend for constructing buildings is to build higher and higher, and developers tend to compete with one another on heights. Tenants also appreciate a landmark address and politicians are conscious of the symbolic role of high-rise buildings. The international and high technology styles have accompanied nearly all new tall buildings and became landmark of our cities [3]. Nonetheless high-rise buildings are more expensive to construct per square meter, they produce less usable space and their operation costs are more expensive than conventional office buildings. The space efficiency, as well as the shape and geometry of the high-rise building need to satisfy the value and cost of the development equation. Space efficiency, which is determined by the size of the floor slab, dimension of the structural elements and rationalized core, goes along with the financial benefit. The building shape is one of the most important considerations in the conceptual stage of building design. Since the building shape determines the size and the orientation of the exterior envelope exposed to the outdoor environment, it can affect building performance in many aspects: energy efficiency, cost and aesthetics. Too often, however, decisions on the building shape are based on aesthetics only, which has the evident disadvantage of limiting the potential of performance improvement. Shape optimization can help overcome this disadvantage by exploring more design alternatives at the conceptual design stage for specific criteria such as environmental and economic performance [4,5].

\footnotetext{
${ }^{*}$ Corresponding author: Md Mehedi Hasan

School of Civil Engineering and Architecture, Kunming University of Science and Technology 650500, China

Department of civil Engineering, Stamford University Bangladesh, Dhaka-1217, Bangladesh.
} 
In this research work, to examined all aspects of lateral loads consideration in the investigate of RCC structures. On other hand, examine the impacts of lateral loads on various structural outer shape of high rise building particularly circular and square floor system in terms of auto lateral load to stories, maximum story drift, story shear as well as overturning moment. The main focus to determine the best structural shape between circular and square under same regular loading.

\section{Material and methods}

The whole study was carried out based on few considerations and specifications which are summarized below.

\subsection{Design code}

\subsubsection{Description}

- American Concrete Institute (ACI) Building design code, 2011 [7].

- Bangladesh National Building Code (BNBC), 1993 [6].

- Uniform Building Code (UBC), 1994 [8].

\subsection{Loadings}

\subsubsection{Description}

- Floor plus ceiling finish $=30$ psf.

- Live load $=40$ psf for Residential floors.

- Partition wall=70 psf for Residential floors.

- Earthquake and wind load are considered.

\subsection{Building components}

\subsubsection{Description}

- $\quad$ Column type $=$ Tied

- Footing type $=$ Mat foundation

- $\quad$ Thickness of all walls $=5$ inch

\subsection{Material properties}

- Yield strength of reinforcing bars, fy $=60,000$ psi.

- Concrete compressive strength, $\mathrm{f}^{\prime} \mathrm{c}=4,000 \mathrm{psi}$.

- Normal density concrete having wc $=150 \mathrm{pcf}$.

- Unit weight of brick, wb $=120$ pcf.

\subsection{Load Calculation}

\subsubsection{Load case according to the BNBC code [6]}

- $1.00 \times \mathrm{DL}+1.00 \mathrm{LL}$

- $1.40 \times \mathrm{DL}+1.70 \times \mathrm{LL}$

- $1.05 \times \mathrm{DL}+1.275 \times \mathrm{LL}+1.275 \mathrm{WLX}$

- $1.05 \times \mathrm{DL}+1.275 \times \mathrm{LL}+1.275$ (-WLX)

- $1.05 \times \mathrm{DL}+1.275 \times \mathrm{LL}+1.275 \mathrm{WLZ}$

- $1.05 \times \mathrm{DL}+1.275 \times \mathrm{LL}+1.275(-\mathrm{WLZ})$

- $1.05 \times \mathrm{DL}+1.275 \times \mathrm{LL}+1.4025 \mathrm{EQX}$

- $1.05 \times \mathrm{DL}+1.275 \times \mathrm{LL}+1.4025(-\mathrm{EQX})$

- $1.05 \times \mathrm{DL}+1.275 \times \mathrm{LL}+1.4025$ (EQZ)

- $1.05 \times \mathrm{DL}+1.275 \times \mathrm{LL}+1.4025$ (-EQZ) 


\subsection{Dead loads}

- Self-weight of edge slab for residential floor $=$ psf

- $\quad$ Floor finish = 30 psf

- $\quad$ 5" Partition wall Load for residential floor $=70$ psf

- Total dead load of 5" slab thickness for residential floor = slab thickness load + Floor finish load + partition wall load $=\left(\frac{5}{12} \times 150\right)+30+70=62.5+30+70=162.5$ psf

\subsection{Seismic load calculation [6-8]}

- Height of building $=200 \mathrm{ft}=60.97 \mathrm{~m}$

- $\quad$ Seismic zone Coefficient (Dhaka zone) $=0.150$

- Special moment resisting frame, $\mathrm{R}=12$

- Importance Coefficient for residential building, I = 1.0

- Vibration time period, $\mathrm{T}=1.07$ second

- $\quad$ Soil profile, $\mathrm{S}=1.5$

\subsection{Wind load calculation [6-8]}

- Square Shape Structure-

- Length of building, B = $90 \mathrm{ft}$

- Width of building, $\mathrm{L}=90 \mathrm{ft}$

- Height of building, $\mathrm{H}=200 \mathrm{ft}$

- Wind pressure in Dhaka city, $\mathrm{Vb}=210 \mathrm{Km} / \mathrm{h}$

- Importance coefficient, $\mathrm{I}=1.0$

\subsection{Square Shape Structure}

- $\quad$ Length of building, B $=90 \mathrm{ft}$

- Width of building, $\mathrm{L}=90 \mathrm{ft}$

- Height of building, $\mathrm{H}=200 \mathrm{ft}$

- Wind pressure in Dhaka city, $V_{b}=210 \mathrm{Km} / \mathrm{h}$

- $\quad$ Importance coefficient, $I=1.0$

\subsection{Circular Shape Structure}

- Diameter or least horizontal dimension of building, $\mathrm{D}=51 \mathrm{ft}=15.5 \mathrm{~m}$

- Height of building, $\mathrm{H}=200 \mathrm{ft}$

- Wind pressure in Dhaka city, $\mathrm{Vb}=210 \mathrm{Km} / \mathrm{h}$

- $\quad$ Importance coefficient, I = 1.0

\section{Results and discussion}

\subsection{Comparison based on Different Influencing Factors}

Comparative analysis was done by ETABS. The global X-axis of the model is parallel to the long direction and global Yaxis is parallel to the short direction of the building. The global X-axis and Y-axis of the two models are shown in Figure 1. To illustrate the different phase of response curves due to lateral loadings in both $X$ \& $Y$ direction, and to set comparison these responses, the whole discussion is going to focus on the effects of wind and earthquake separately. 

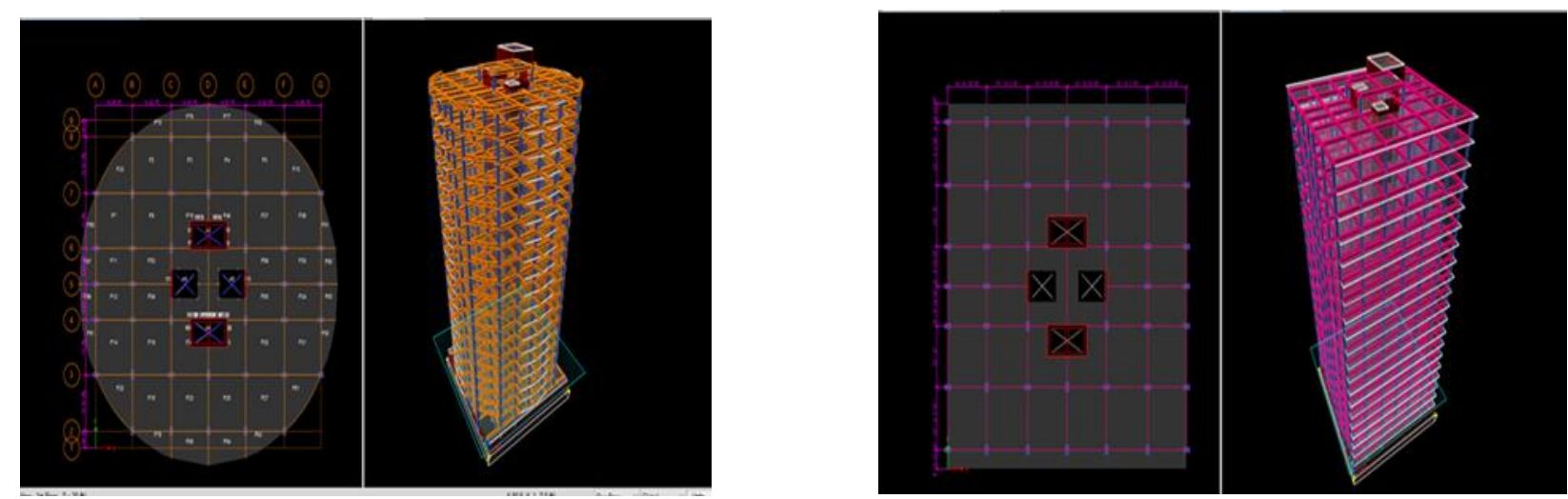

Figure 1 Global X \& Y Direction of ETABS Model (Circular + square)

\subsection{Response due to Wind Loads}

\subsubsection{Lateral loads due to WIND resisted by the Stories}

Here the horizontal axis represents lateral loads in kips and the vertical axis represents the stories of the building. Blue curves state the response due to lateral loads implying in X direction of the model and red curves in Y direction. Also comparisons between lateral loads resisting capacities of Square and Circular shape in X and Y direction are clearly figure 2. From figure it is clearly seen that, response curves are near about symmetric in both Square Shape Structure and Circular Shape Structure while the value changes gradually in each story. It shows that the value of lateral load due to both WX and WY increases gradually from Ground Floor to 18th floor.
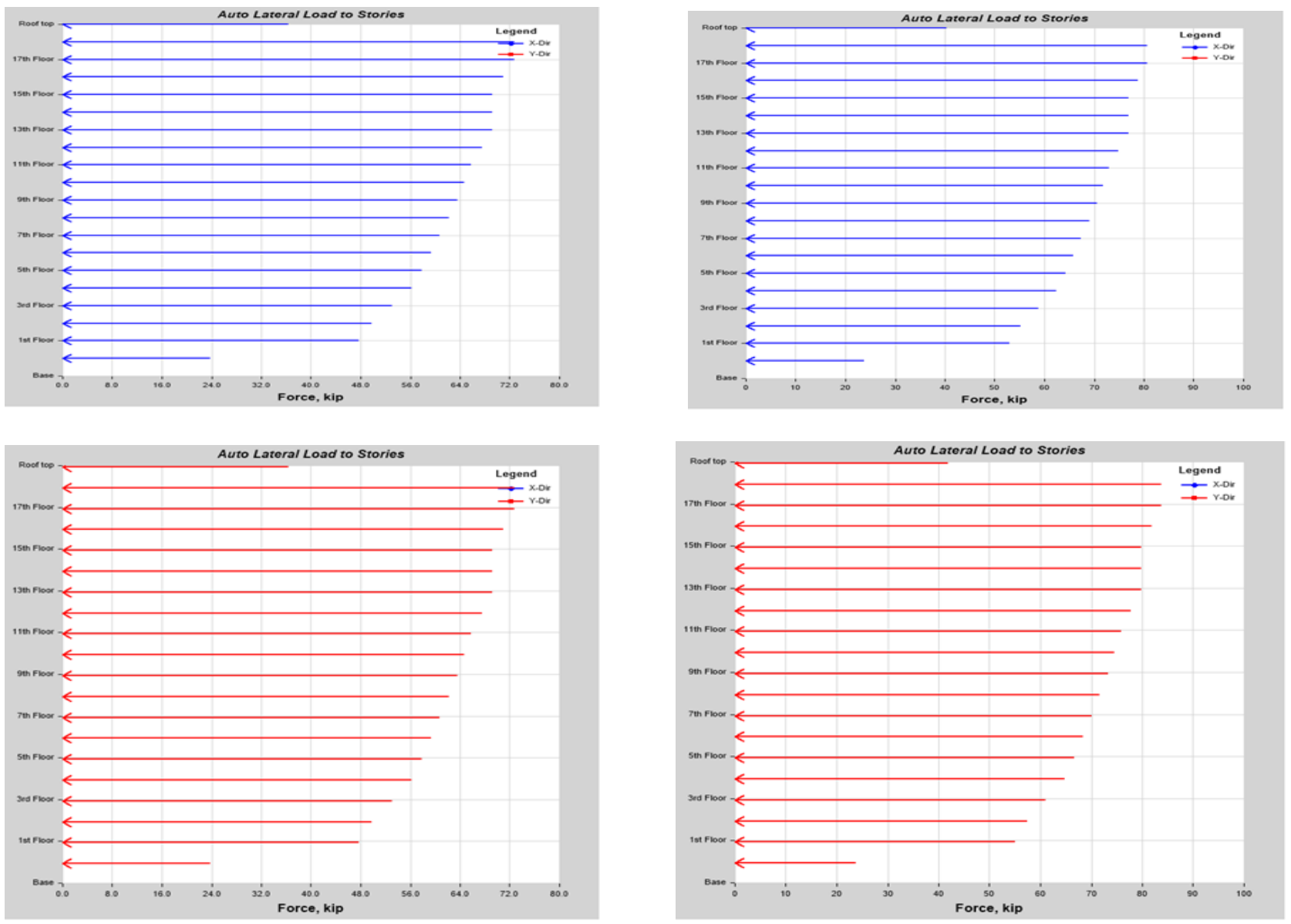

Figure 2 Resisting Wind loads at storeys in global X direction and Y direction 


\subsubsection{Maximum Story Displacement due to WIND resisted at each storey}

Here the horizontal axis represents displacement in inch and the vertical axis represents the stories of the building. Blue curves state the response due to lateral loads implying in X direction of the model and red curves in Y direction. Also comparisons between displacements of Square and Circular shape in X and Y direction are clearly shown in figure.
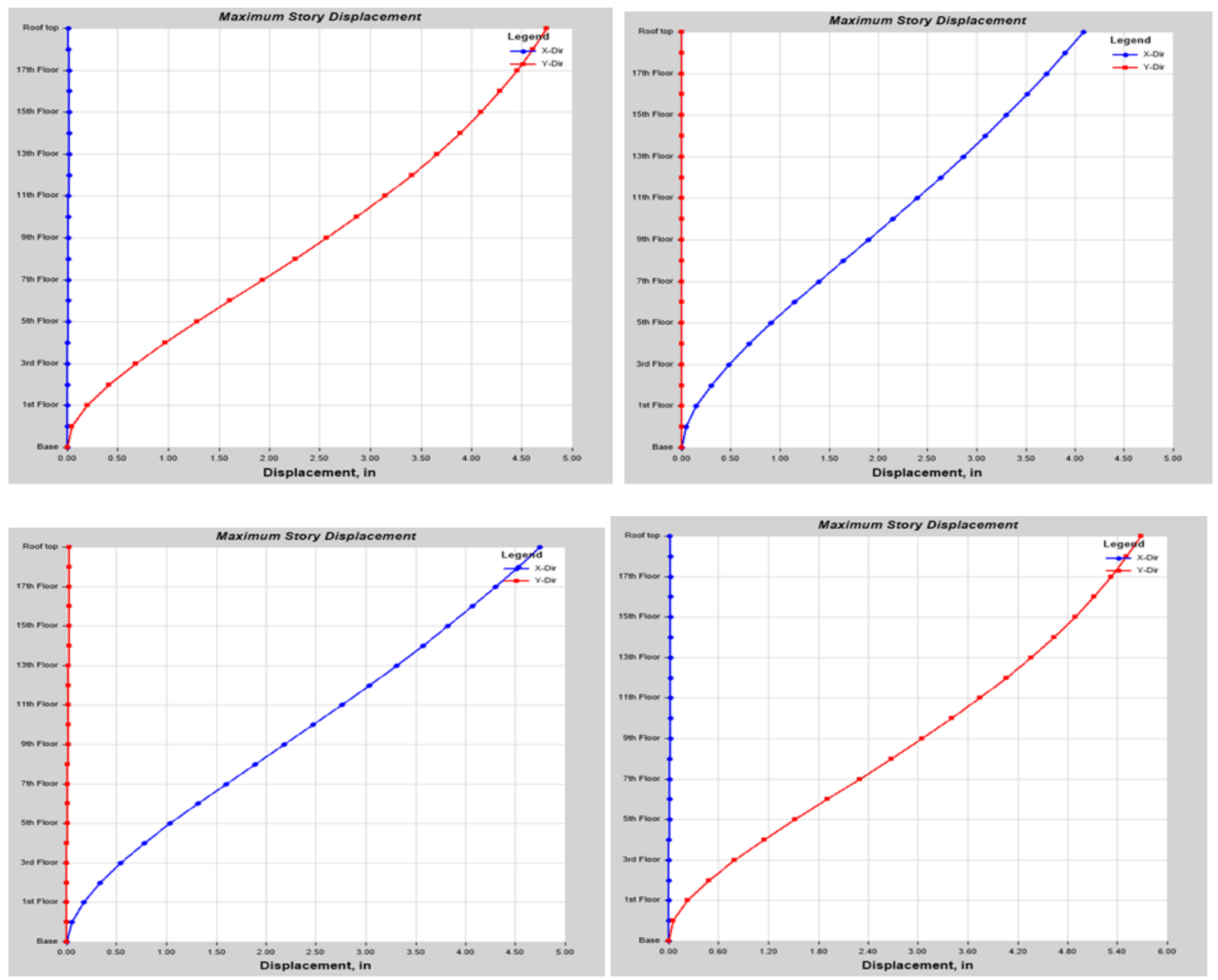

Figure 3 Maximum Story Displacement due to Wind loads in global Y and X direction

From figure it is clearly seen that curve starts from base and sharply goes on Roof Top in both WX and WY. The displacement curve of Square Shape Structure fluctuates slightly from the displacement curve of Circular Shape Structure in WX. Fluctuation occurs similarly in WY.

\subsubsection{Maximum Story Drifts}

Here the horizontal axis represents drifts and the vertical axis represents the number of the stories of the building. Blue curves state the response due to lateral loads implying in X direction of the model and red curves in Y direction.

\subsubsection{Resisting Story Overturning Moments [MR]}

Curve starts from base with its peak value and sharply goes down to18th story in both WX and WY. It is noted here that due to lateral loads in $\mathrm{X}$-direction, the whole structure will resist its overturn with respect to Y-axis and creates a resisting overturning moment MR with respect to Y-axis as shown in figure below. Similar case can be explained for loads in Y-direction. However, it is shown that circular shape structure can withstand greater storey overturning compared to square shape structure. Horizontal axis represents overturning moments in kip-inch and the vertical axis represents the stories of the building. Blue curves state the response due to lateral loads implying in X direction of the model and red curves in Y direction. 
Table 1 Story Overturning Moments due to Earthquake loads in global X direction.

\begin{tabular}{|c|c|c|}
\hline \multirow[b]{2}{*}{ Story } & Square & Circular \\
\hline & $\begin{array}{c}\text { Resisting Overturning Moment } \\
\text { kip-ft }\end{array}$ & $\begin{array}{c}\text { Resisting Overturning Moment } \\
\text { kip-ft }\end{array}$ \\
\hline Roof top & 150.3171 & 167.2066 \\
\hline 18th Floor & -978.6687 & -1002.8975 \\
\hline 17th Floor & -2851.53 & -2990.4328 \\
\hline 16th Floor & -5453.9915 & -5733.1131 \\
\hline 15th Floor & -8705.4654 & -9189.0285 \\
\hline 14th Floor & -12567.8211 & -13316.2689 \\
\hline 13th Floor & -17002.9252 & -18072.9237 \\
\hline 12th Floor & -21972.6456 & -23417.0836 \\
\hline 11 th Floor & -27441.5982 & -29309.1792 \\
\hline 10th Floor & -33374.554 & -35709.934 \\
\hline 9th Floor & -39732.9104 & -42577.024 \\
\hline 8th Floor & -46478.0661 & -49868.1246 \\
\hline 7th Floor & -53571.4184 & -57540.9111 \\
\hline 6th Floor & -60974.3646 & -65553.0596 \\
\hline 5th Floor & -68648.3021 & -73862.2453 \\
\hline 4th Floor & -76555.2626 & -82426.688 \\
\hline 3rd Floor & -84657.1863 & -91204.5586 \\
\hline 2nd Floor & -92915.2345 & -100153 \\
\hline 1st Floor & -101291 & -109230 \\
\hline GF & -109754 & -118394 \\
\hline Base & -118255 & -127593 \\
\hline
\end{tabular}

Table 2 All comparison table

\begin{tabular}{|c|c|c|c|c|c|c|c|c|c|}
\hline \multirow{2}{*}{ Topic } & \multirow{2}{*}{$\begin{array}{l}\text { Story } \\
\text { Level }\end{array}$} & \multicolumn{4}{|c|}{ Square Shape Structure } & \multicolumn{4}{|c|}{ Circular Shape Structure } \\
\hline & & EQX & EQY & WX & WY & EQX & EQY & WX & WY \\
\hline \multirow{2}{*}{$\begin{array}{l}\text { Lateral Loads } \\
\text { to Stories } \\
\text { (kip) }\end{array}$} & GF & 4.117 & 4.117 & 23.752 & 23.752 & 3.961 & 3.961 & 23.752 & 23.752 \\
\hline & Top Floor & 116.294 & 116.294 & 72.713 & 72.713 & 120.574 & 120.574 & 80.693 & 83.802 \\
\hline \multirow{2}{*}{$\begin{array}{l}\text { Maximum } \\
\text { Story } \\
\text { Displacement } \\
\text { (inch) }\end{array}$} & GF & 0.035426 & 0.035917 & 0.044409 & 0.046742 & 0.037827 & 0.04005 & 0.049727 & 0.055342 \\
\hline & Top Floor & 4.040148 & 4.483857 & 4.086595 & 4.745737 & 4.424742 & 5.023357 & 4.747572 & 5.679509 \\
\hline \multirow{2}{*}{$\begin{array}{l}\text { Maximum } \\
\text { Story Drifts }\end{array}$} & GF & 0.000295 & 0.000299 & 0.00037 & 0.00039 & 0.000315 & 0.000334 & 0.000414 & 0.000461 \\
\hline & Top Floor & 0.00181 & 0.001453 & 0.001681 & 0.001256 & 0.002043 & 0.001641 & 0.001972 & 0.001536 \\
\hline \multirow{2}{*}{$\begin{array}{l}\text { Story Shears } \\
\text { (kip) }\end{array}$} & GF & -849.581 & -849.62 & -1192.601 & -1192.644 & -919.412 & -919.437 & -1320.9 & -1370.904 \\
\hline & Top Floor & -108.581 & -108.582 & -36.357 & -36.357 & -112.479 & -112.479 & -40.347 & -41.901 \\
\hline $\begin{array}{c}\text { Story } \\
\text { Overturning } \\
\text { Moment (k- } \\
\text { in) }\end{array}$ & Basement & -118255 & 115574.2095 & -133088 & 130623.4292 & $-127 \$ 93$ & 124573.8316 & -147665 & 150347.2893 \\
\hline \multirow{2}{*}{$\begin{array}{l}\text { Story Stiffness } \\
\text { (kip/in) }\end{array}$} & GF & 24621.4045 & 23804.8294 & 26870.0794 & 25644.8372 & 24362.6869 & 23262.5152 & 26580.6041 & 25068.6709 \\
\hline & Top Floor & 1073.2005 & 1335.9351 & 360.5034 & 482.3509 & 984.246 & 1225.1935 & 340.9998 & 454.6619 \\
\hline
\end{tabular}




\section{Future suggestions}

Based on the intentions, possibilities and limitations of the study (stated in Chapter I), some suggestions can be projected for future studies:

- This study was accompanied based on 15 storied Square Shape floor systems, further examines considering other floor system such as flat slab can be considered to see the modification in moment, shear, axial forces etc. in different building elements and also their cross sectional dimensions as well strengthening necessities.

Sway and deflection control may be measured in investigation.

\section{Conclusion}

After this research work determined that, Circular Shape structure shows greater story displacement at top floor due to the effects of wind and earthquake compared to the Square Shape structure. As well as Square Shape structure can resist higher story overturning moment at base due to earthquake/winds effects compared to circular shape structure. Also work showed that, square shape structure can resist higher story shear at base and lateral loads at top story due to earthquake/winds effects compared to circular shape structure. And the main findings of this study the circular shape structures have higher story drift compared to square shape structure.

\section{Compliance with ethical standards}

\section{Acknowledgments}

Authors delightfully acknowledge the Department of Civil Engineering of Stamford University Bangladesh, Dhaka, Bangladesh for supporting this study. We are very much grateful to our supervisor, Md. Mahbub-ul-Alam, Assistant Professor of the (Department of Civil Engineering, and Stamford University Bangladesh) for his continuous suggestions. Authors also acknowledge the sincere efforts of Dr. Ghulam Murtaza Rana (Kunming University of Science and Technology, China) in improving the final draft of this research paper.

\section{Disclosure of conflict of interest}

The author have no conflict of interest.

\section{References}

[1] Newman P, A Thornley. Planning World Cities: Globalization and Urban Politics. Palgrave Macmillan. 2011.

[2] Sev A, A Özgen. Space Efficiency In High-Rise Office Buildings. METU Journal of the Faculty of Architecture. 2009; 26(2): 69-89.

[3] Architecture, Banal Nationalism and Re-territorialization, DONALD MCNEILL and MARK TEWDWR-JONES.

[4] Wang W, H Rivard, R Zmeureanu. Floor shape optimization for green building design. Advanced Engineering Informatics. 2006; 20(4): 363-378.

[5] Shape effects on the wind-induced response of high-rise buildings.

[6] Bangladesh National Building Code, 1st Edition, City Art Press, Dhaka, Bangladesh. 1993.

[7] American Concrete Institute Building Design Code, ACI, New York, USA. 2011.

[8] Uniform Building code, Structural Engineering Design Provisions. 1994; 2. 